\title{
REVIEW
}

\section{Challenges and issues of STEM education}

\author{
Anjum Qureshi $^{1^{*}}$ Nazir Qureshi $^{2}$ \\ ${ }^{1}$ RCERT (Nagpur University), Chandrapur, India \\ ${ }^{2}$ Social Activist, Chandrapur, India
}

\section{Check for updates}

Correspondence to: Anjum Qureshi, RCERT (Nagpur University), Chandrapur, India;

Email: anjnaznus@gmail.com

Received: August 24, 2021;

Accepted: October 17, 2021;

Published: October 21, 2021.

Citation: Qureshi, A., \& Qureshi, N. (2021). Challenges and issues of STEM education. Adv Mobile Learn Educ Res, 2021, 1(2), 146-161.

https://doi.org/10.25082/AMLER.2021.02.009

Copyright: () 2021 Anjum Qureshi \& Nazir Qureshi. This is an open access article distributed under the terms of the Creative Commons Attribution License, which permits unrestricted use, distribution, and reproduction in any medium, provided the original author and source are credited.

\begin{abstract}
Science, Technology, Engineering, Mathematics, abbreviated as STEM, is a promising field with increasing popularity due to its benefits in the modern world of globalization and modernization. Science and mathematics are the basics of the technological developments going on in the world. Thus, the children should be motivated to learn STEM from early school days. The minds of small kids are like a sponge, and they can grasp everything quickly. STEM education should be encouraged from childhood so that children like it and continue with it for higher education. This chapter discusses some of the challenges observed while encouraging children to learn STEM early and lists solutions.
\end{abstract}

Keywords: STEM education, play based learning, gender gap

\section{Introduction}

Today, we are experiencing the 4th Industrial Revolution (IR), which increased academics, businessmen, politicians, and media outlets refer to, and directly affects the worldwide workforce as it requires workers with new skills (Papadakis \& Kalogiannakis, 2020). Industrialization, digitization, and automation have brought the entire world to our fingertips. Gone are the days when we had to stand in a line to pay electric or phone bills. We can pay bills and order anything at our leisure using our smartphones. The technological developments around the globe are occurring rapidly due to the numerous researches. Science, Technology, Engineering, and Mathematics (STEM) education plays a significant role in enabling the next generation of innovators. Traditional teaching and learning practices must be transformed to respond to the modern workplace's evolution and prepare the future labor force (Tzagkaraki et al., 2021). The teacher also needs to transform his role and, consequently, his profession and act as a researcher, as new knowledge is continually being revised (Chatzopoulos et al., 2021). However, none would be essential if these changes are not focused on the curriculum (Vidakis et al., 2019).

STEM education has many advantages as it is an innovative and attractive tool for students of all ages. It is an exciting field for children to satisfy their curiosity about the world. According to research, STEM activities actively engage students and encourage autonomous learning and motivation (Poultsakis et al., 2021). With STEM education, students can represent not concrete concepts by improving their understanding of school content but also the whole world by making conceptual models and growing 'visual and conceptual understanding' of an idea. Besides, the possibility of using robotics in subjects such as history, arts, and literature can help students improve their knowledge and skills and make their teaching more exciting and engaging through active interaction.

Numerous organizations are investing in promoting STEM to fulfil the increasing demands of fast and comfortable technologies. These organizations are making efforts to provide opportunities for students to learn STEM concepts more quickly. Several measures have also been taken to make the learning process more interesting by using distinctive techniques. However, several challenges need to be addressed while imparting STEM education among children and innovators. The challenges or the issues might vary according to the age groups, location, and people's demands. Nevertheless, these innovations are either confined to developed countries or metro cities. Most of the global population still lacks access to novel technologies. Therefore, it is essential to increase the scope of STEM education to foster the availability and adaptability of novel technologies worldwide.

Most of the children start losing their interest in science and mathematics during school days. It is because many concepts are virtual and have to be imagined. For example, though everyone uses mobile and the internet, it is difficult to explain how the information is transferred wirelessly. They are unable to relate the theories studied in the classroom with the real world. 
One more difficulty faced by the students is that they are not allowed to work on real projects. The education curriculum starts with theories with no time left for the students to practice the class concepts, think about them, and change the existing techniques. Due to this, they cannot figure out the shortcomings of the current technology and develop better options for it. One of the critical challenges of STEM education is the gender gap. There is a gap in the male to female ratio of population in the world.

Similarly, a gender gap exists in the field of STEM education. The number of females pursuing STEM is less than the number of males at the school level. Still, this gap increases at higher levels of education. The ratio becomes more disproportionate in the organizations investing in STEM as fewer women opt for jobs. There are many factors responsible for the gender gap, and these factors may vary according to different countries or regions. For sustainable development of nations and the flourishing of STEM industries, colleges, schools, or educational institutions must succeed in developing interest in science, Mathematics, and engineering among children at a very young age. The students should be empowered to transform their creative ideas into reality and learn the skills that are required by the STEM industries.

In this paper, we would like to discuss some of the challenges faced while imparting STEM education. One of the challenges is the development of innovative teaching methods. Due to lack of resources and insufficient knowledge, it is challenging to develop new teaching methods that would be interesting. The traditional exam pattern is another factor that slows down the process of developing STEM education. Using interactive and innovative methods requires more time. The teachers and the students need to be active and spend extra hours on novel techniques. Due to the time-bound organizational culture and more importance for the academic scores, the teachers must concentrate on exam patterns. It is therefore not possible for the teachers to utilize innovative methods to their full extent. Another challenge is that teachers reach specialization for a particular subject. It becomes difficult for them to inter-relate the core subjects and STEM as they lack an understanding of the concepts and standards of other subjects.

The challenges and similar solutions for them will vary according to the age group and location or place. This chapter will concentrate on the challenges faced in implementing STEM education for preschoolers and children in the early years. The layout of the chapter will be as follows: Section 2 will discuss how play-based methods can be developed and implemented for the students. Section 3 will discuss the hurdles observed in developing new strategies and some of the stereotypical factors that need to be addressed to create the latest teaching methods successfully. Section 4 will try to brief out how the students should be encouraged to work on real-life projects. Section 5 will discuss the reasons behind the gender gap in STEM education and the measures to overcome this problem. Section 6 will conclude the chapter. This chapter will help identify some of the challenges in implementing STEM education and list some possible solutions to tackle this. It will be helpful to increase the interest in STEM education among students, teachers, and parents so that everyone can cope with the fast-developing world.

\section{Development of play based learning for STEM}

The children in the age group of 3 to 5 years are called preschoolers. According to a report published in 2018 by the Lego Foundation and UNICEF (The Lego Foundation in Support of UNICEF, 2018), social, emotional, and cognitive skills are rapidly being developed during the preschool period. Children like to play, and for most of them, it is the only activity they enjoy throughout the day (Teaching tolerance project, 1997). Learning through playing, singing, and interacting during the preschool days, help the children to develop their imagination and creativity. Similarly, play-based learning can strengthen the learning and motivation for the children studying in the early grades of the school who are 6 to 8 years old. Play-based learning can therefore be considered as an essential strategy for learning and teaching STEM.

In this context, the scientific community regards technology in early childhood education settings as a tool to prepare students and future citizens for their role in society (Papadakis \& Kalogiannakis, 2017; 2019; 2020). Additionally, research supports that the preschool classroom environment is rich in preschoolers' connections and opportunities to engage actively in Science, Technology, Engineering, and Mathematics (STEM) activities. Nowadays, there are numerous educational tools available for preschool-age children to engage them in STEM activities such as visual block-based environments (e.g., ScratchJr), online environments (e.g., Code.org), robotic devices (e.g., Bee-bot), and unplugged activities (Papadakis et al., 2021).

In preschool classrooms, the educational goal is not to introduce coding literacy in separate subject classes. Indeed, the aim is to teach students how to use digital technologies to produce well-educated people. In preschool education, the aim is to ensure a broader focus so that 
students use the digital technologies and the CT and coding activities as learning opportunities for cognitive growth, creative problem solving, and entrepreneurship (Vaiopoulou et al., 2021).

\subsection{Attributes of playful experiences}

A child is curious right from their birth. They want to know about the world around them. This curiosity among the kids can be nurtured playfully for imparting STEM education. The learning process through play can be fruitful if it is joyful, fosters interaction, and keeps the children engaged. Some of the components of playful experiences are (Lego Foundation, 2017):

\section{(1) Joyful}

The teaching methods or the activities used for STEM education must be a joyful and enjoyable experience. Joy or thrill is the heart of the play. The students can learn well if they are exposed to an environment full of excitement. The children are happy and content when they can complete their tasks in a fun-filled and friendly environment.

\section{(2) Engaging}

Another critical attribute of a playful experience is that the activities should be engaging. The children should be fully absorbed in their activities. Such actions will develop their critical thinking and innovative thinking abilities. Availability of STEM education at an early stage of life can strengthen the understanding of children towards concepts of science and mathematics. The children can use these concepts during class and in their daily life. (see Figure 1)



Figure 1 Attributes of Playful Experience (Source: The Lego Foundation in Support of UNICEF, 2018)

\section{(3) Meaningful}

Play-based activities should help the children to explore and understand what they have seen or done. They should be able to relate the new experiences with those already known to them. By such activities, a child will see science and numbers as a part of everyday life.

(4) Iterative

Activities implemented playfully should be iterative. The exercises should encourage the children to find out various possibilities for a given task, or they should be able to find out different solutions for the given problem. The children should be able to work independently as well as with others while performing the assigned tasks.

\section{(5) Interactive}

One more characteristic of play-based learning is that it should promote interaction for the kids. The games used to teach the STEM concepts should interact with their teachers and counterparts. They should be able to express their view and at the same time freely raise questions or queries so that they can learn the concepts well.

\subsection{Barriers in implementation of play based activities}

STEM can be made interesting during the preschool and early school days by adopting play-based learning as a fundamental method for educational programs. Play-based learning has attracted the attention of academicians in recent years. Learning is enhanced when a research process is followed. Based on a project, students design, program, and interact with the robot. They need to think about the problem and evaluate and re-evaluate their ideas at each process stage. To find the solution, students observe, cope with the external conditions, and identify the effects on the robot's behavior, try and correct mistakes (Ampartzaki et al., 2021). In this context, kids foster their critical thinking and the most important, adopt the ability to apply their knowledge in a wide range of similar situations. Students improve their creativity and imagination through the process of creating a STEM project. From the beginning, they plan what they will build based on the goal they want to accomplish. They make assumptions and 
imagine their operation. At the same time, they can do self-criticism and receive feedback on their effort. Students actively engage in robotics projects, following a series of logical steps, combining fun with learning, which adopts a metacognitive and humanistic character. As they are active and experimenting, shape their understanding of the world. Knowledge becomes more valuable and lasts longer in memory than they are just listeners and are called to memorize information. The playful nature of robotics is essential in primary education so young students can take the initiative and action (Papadakis et al., 2021). There are still several obstacles in integrating play as a medium of education for STEM subjects. The gap between play and traditional teaching STEM is more in the rural areas of developing countries than in developed countries and metro cities. The integration of play-based learning for STEM must be done by considering three critical elements of education, i.e., teacher, parents, and children. Some of the barriers observed teachers during the implementation of play during class are as mentioned below:

\section{(1) Teachers perspective}

Teachers feel that there should be a limit to the number of students in a class while conducting play for imparting knowledge related to STEM. As STEM is a diverse field, the activities involved require teachers to interact with the students directly. If the number of students is more, it is difficult for the teachers to reach or personally attend to all the students to monitor their activities. In such circumstances, teachers feel that their efforts are not fully utilized. They are under pressure that their teaching is unable to comply with the high academic standards of the education curriculum. Another possibility is that the teachers are sometimes uncertain about their roles in the classroom. They find it challenging to maintain a balance between teacher-led instructions and child-led free plays. The teachers cannot follow a fixed schedule while using play during class as some of the activities may require more time to complete. Teachers should be competent enough to handle the students during child-led play not to lose control of the class. In such situations, they may fail to enhance the academic learning of the students (Angela et al., 2018). It should not be overlooked that many teachers have not been systematically involved in programming, science, or other STEM courses since their studies. This implies difficulties in implementing educational robotics activities in practice and low levels of self-confidence. Teachers' knowledge can be updated with workshops to design and use robotics packages (Papadakis, 2020; 2021).

\section{(2) Characteristics of student}

Another barrier in the integration of play with classroom teaching is the behavior and expectations of the students. The family and community environment are an essential element in shaping the mental status of children, their language preferences, and their love of playing. The play curriculum cannot be the same for children from any part of the world. Similarly, while introducing the children to the STEM concepts, the play curriculum must be designed for viewing the children's surroundings and language preferences. For example, the children living in metro cities or towns may be familiar with English or any other foreign language that is spoken widely in their country. Still, the children from rural areas will prefer the activities that could be conducted in local languages. Another essential feature is that there can be variations in the preference of children for play. Some of them may prefer activities to be conducted in groups. Some may like more physical activities, while some may be attracted to the activities that involve utilizing the brain. The expectations of children are different. Therefore, while designing the curriculum based on play, all these factors have to be considered. It is demanding that a single activity will fulfill the hopes of all the stakeholders. The educationists have to be, therefore, very careful while developing activities. They have to be equally cautious to create a wide range of activities after studying students' mentality and emotional status to find interest in some activities. The students will lose their interest in STEM if none of the play-based exercises can meet their expectations. According to some of the researchers, indirect involvement of children through surveys or questionnaires should be encouraged to know the preferences and expectations of the students and then use the collected data for designing child-friendly activities (Jarmila et al., 2019).

\section{(3) Lack of awareness among parents}

Many of the parents believe that play-based learning would take away their wards from academics. Some parents expect their kids to attain high academic achievements in mathematics and science to build a lucrative career. The parents believe that academics involve books, lectures, and assignments. They are under the misconception that play-based learning is timeconsuming. More involvement in play would divert the student's attention from the books and classroom teaching (Tay et al., 2017). 


\section{Factors affecting the successful implementation of innovative teaching methods for STEM}

The process of strengthening and executing innovative teaching methods and integrating play-based learning can be done by addressing the problems and moving forward. The solution cannot be obtained by tackling one challenge at a time. Moreover, as the challenges may differ from place to place, similarly, the answers and the mechanisms will vary. However, still, the obstacles can be removed by paying equal attention to all the challenges. An enabling environment is required to foster the process of generating interest among the students for STEM education. Most developed countries have realized its importance but still need to tackle the situation in an integrated manner by looking at social, national, and financial conditions. The common challenges discussed in most literature are financing, teacher's development, and involvement of parents and the community (STEM 2026, 2015; Marisel et al., 2018; Ejiwale, 2013; Susilo \& Sudrajat, 2019). (see Figure 2)



Figure 2 Factors affecting implementation of Innovative teaching methods for STEM

\subsection{Finance}

The arrangement of sufficient resources to implement innovative and play-based pedagogy for STEM is sometimes limited due to the availability of expenditure. Along with the textbooks, there is a requirement for learning materials, educational equipment, software, gadgets, and professional support to create a friendly environment for the children. The teaching methods should be educational and also entertaining to generate interest among the kids towards STEM. Good quality teaching equipment is sometimes not affordable by the schools in rural areas. However, as preschool and primary level education plays a crucial role in sculpting the lives of children, lack of funds should not be a limitation. This section will try to bring out some measures so that shortage or unavailability of funds does not interfere with the child-friendly pedagogy methods.

\section{(1) Local resources}

Play-based learning resources can be developed by using local and low-cost materials that are readily available. The local toys and games can be modified to promote the learning of STEM among the kids. The learning materials are costly, but they should be relevant enough to implement quality-based education.

\section{(2) CSR funds}

The funds for the learning equipment can be arranged by seeking help from the local government organizations. The companies' act 2013 has opened the doors for using the Corporate Social Responsibility (CSR) funds for education (A study report compiled by United Way Mumbai and CSR Box, 2018). The school authorities and the local organizations can try to contact the nearby industries and request them to allocate CSR funds to develop the quality of education in the schools. The funds generated through CSR can be used for buying educational equipment. It can also be used in educational promotion activities like scholarships, sponsorships, and children from economically weaker sections for higher education.

\section{(2) Alumni}

The alumni can play a positive role in transforming the educational status of an educational institution. According to the Alumni Engagement Study of 2019 by UC San Diego's Center for Research in Educational Equity, Assessment and Teaching Excellence (CREATE) (UC San Diego's Center for Research in Educational Equity, 2019), many former students have an intense desire to reconnect, help, and advise the students. Alumni associations are generally formed at 
the higher level of education. The schools can encourage the formation of such associations in the early school days. The latest technology and the craze for social media platforms have united the school folks. Visiting old schools and childhood friends has become a trend for many in the past few years. The schools should try to keep track of the alumni as they are always ready to contribute to the advancement of schools that have sculpted their future. With the financial support for the infrastructural development and upgrading the educational facilities, these former students can motivate the current ones. They can assist the students in career building. As far as STEM education is concerned, all those who have built their career based on STEM will be role models for the students. The experiences of the alumni can also help to remove some of the misconceptions of STEM education prevalent in society and thus contribute toward quality education.

\subsection{Involvement of teachers in rural areas}

Teaching is considered a noble profession \& teachers are regarded as Gods in many societies. In this chapter, we are discussing STEM education. Still, teachers' overall development is a primary requirement for making the teaching-learning process more fruitful. Lack of qualified teachers for STEM is one factor that affects the smooth implementation of innovative teaching methods. Well-prepared, qualified teachers equipped with training on the latest changes in the education curriculum are required for the academic enrichment of the students. This gap of good education and qualified teachers is more in the small towns and villages. Some of the factors responsible for the lack of teachers for STEM in rural places are:

(1) Due to the geographical location and lack of basic amenities, the teachers are unwilling to work in rural areas. The schools in rural areas struggle to find teachers with higher-level content. Some teachers may opt to work at a rural school, but they prefer staying nearby. A teacher thus spends a significant amount of time travelling. The teacher cannot give in extra effort and time needed to generate interest among the students for STEM and develop an atmosphere where the students will enjoy learning.

(2) Another problem observed in the remote and rural areas is the lower salary and inconsistency in its payment. This factor aggravates the problem of finding good teachers for the students of small villages.

(3) Training of the teachers at regular intervals can improve their pedagogy skills. Suppose the problem of expenses for the teaching materials is solved. As discussed in the earlier section, teachers can help the students develop an interest in STEM. Nevertheless, due to their old age, some teachers are reluctant to adopt the new techniques, especially the teaching methods that use the latest technology. For example, some teachers cannot engage in digital classrooms as they cannot manage modern equipment like computers and projectors. Therefore, the training sessions should be planned in such a way that the teachers are made aware of the new teaching-learning aids and at the same time can learn the techniques of using them in class.

(4) An Insufficient number of teachers is another factor that hampers the conduction of classes. A proper teacher-to-student ratio needs to be maintained at the preschool level as preschoolers require personal attention to understand and conduct STEM activities. In places with insufficient teachers, the preschoolers do not understand the concepts well. Gradually lose interest and feel that they cannot choose STEM during their higher education days or career options.

The teachers need motivation and encouragement to develop themselves and put on little extra effort to increase the acceptance rate for STEM among the kids. STEM can be more interesting if the teachers help the students to learn rather than just teaching the subjects. Some of the methods that the teachers can use to generate interest for STEM subjects among the kids at the initial days of education are:

\section{(1) Inter school visits}

This technique can be a source of encouragement for the teachers as well as the students. There are some schools where the teachers think out of the box. They develop their innovative ideas and work for the overall development of schools and their students. An educational tour to other schools can help in fostering communication with their teachers and students. These practical experiences can be more helpful for the teachers to develop themselves and their teaching techniques. (see Figure 3 and 4)

\section{(2) Recreational activities}

Role-plays and action songs can be powerful methods for teaching STEM to preschoolers toddlers like playing and singing, so the STEM concepts can be explained through these techniques. 


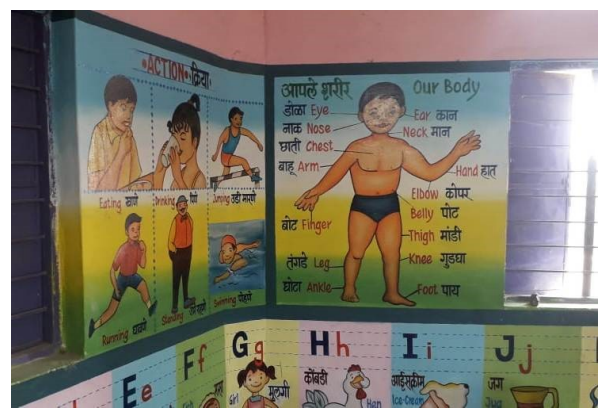

Figure 3 Parts of body written in English and Marathi (local language) in a school

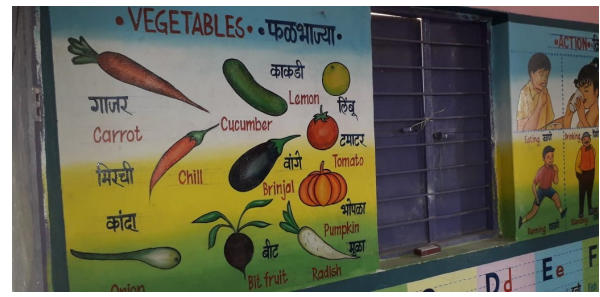

Figure 4 Pictures of fruits and vegetables written in English and Marathi (Local language) in a school

\section{(3) Painting on walls}

Children love colors and pictures. The teachers can utilize these attributes of kids to teach STEM subjects excitingly. The numbers, multiplication tables, and diagrams can be painted on the walls of the school. The teachers can help the local youth to have similar paintings on the border of villages so that the children see the numbers and diagrams while playing or walking through the streets. Some more techniques that can be used for the preschoolers are using tables of different shapes and colors to learn colors and geometrical figures simultaneously. (see Figure 5,6 and 7 )

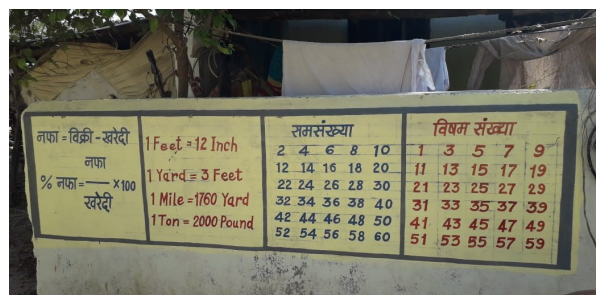

Figure 5 Odd and Even numbers and conversion of units written on wall of a village

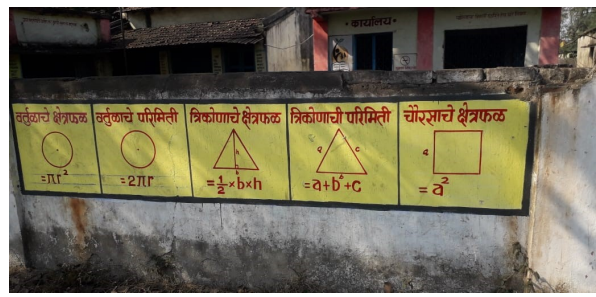

Figure 6 Formulas of area and surface area for circle, triangle and square



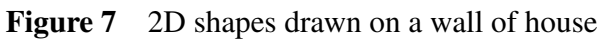




\subsection{Involvement of parents}

Participation of family members in education is essential for developing the literacy and math skills of the children. Educators have started to use research-based approaches to improve family members' involvement to support children's early learning. When the parents are engaged with the children for Math related activities like counting, playing with different shapes, arithmetic operations, etc., such activities show positive results (Frances et al., 2013). In families where the parents lack awareness regarding the importance of activity and play-based education, it is not easy to convince them and cooperate. Some parents are busy with their busy schedules having less time for children. Many believe in the traditional teaching done only with books. Some are not interested in the activities and hesitate to spend on the materials required for its implementation. Many parents have limited knowledge on careers in STEM, especially in information technology and engineering. When the children grow up, they tend to explore career opportunities of their interest. The interest in STEM can be increased among the kids by using innovative techniques and a friendly environment during the early school days. At the same time, children value the influence of their parents. Therefore, it is essential to provide parents with basic information about the benefits of STEM careers. Furthermore, they must know the benefits of interactive and playful learning methods to support their children at the time of career exploration. According to a Microsoft Corporation survey (Harris, 2016), nearly half of the parents in developed countries like the USA prioritize STEM education. In contrast, others prefer their children to select visual arts. It is, therefore, necessary that the measurements given below can be tried to increase the support of parents in teaching STEM to children:

\section{(1) Awareness activities}

To increase the support of parents, the education departments can plan awareness programs, particularly in the villages or in the areas where the level of education is lower among the parents. Street plays can be an informative and entertaining method to disseminate awareness among parents. It is imperative to increase the awareness level of the parents of preschoolers or children in primary classes. Suppose the children are told that STEM is engaging at an early age. In that case, they will never hesitate to continue with STEM education for the rest of life. Their parents greatly influence the children. So, awareness activities are required for the parents to generate interest in STEM. They would encourage their children for the same. Street plays can be an essential tool for awareness as they are performed in the local language so the parents can quickly get the message. The street plays get swiftly completed and do not exert a financial burden on the organizer. The youths and local NGOs can be of great help in organizing street plays.

\section{(2) Fostering interaction with parents}

Teachers and parents are the most direct medium for learning STEM concepts for young children. Some parents believe that STEM topics are for older children or a class of intelligent and brilliant children (McClure et al., 2017). These attitudes and beliefs get transferred to the younger generation. Therefore, the children may hesitate to participate in the STEM learning process. Suppose the parents have a better understanding of the topics. In that case, they will be more confident to introduce STEM ideas and projects to their children. To better understand the parents, the communication gap between the teachers and parents needs to be minimized.

To foster interaction with the parents, the schools should initiate regular parent-teacher meetings so that the parents are informed about the progress of their wards. During these meetings, the teachers should discuss the changes observed in the child due to the interactive teaching techniques for STEM. However, it has been observed that many parents hesitate to talk to teachers and fail to discuss their problems in helping the children with school work. To provide better communication among the parents and teachers, the schools can arrange competitions for parents and grandparents. These competitions can help remove the parents' fear of communicating with the teachers and school authorities.

\section{(3) Microplanning}

Microplanning is a structured planning method that employs all the kinds of available resources to its fullest extent. It has been used as an essential tool for sustainable development in various fields like health care, education, etc. A micro planning model is unique for a locality or village. A model developed for any town cannot be considered a universal solution for the world. It is prepared by the people with the help of participatory techniques. Microplanning has been recognized as an essential tool for improving education (Douma et al., 2020). In this process, the people of a locality/village gather together, identify the problems and barriers in addressing these problems, and suggest solutions to overcome the identified obstacles.

Therefore, micro planning can serve as an essential tool to increase the participation of 
parents and increase their involvement in encouraging the kids for STEM education. The problem areas vary from place to place, and similarly, the solutions for those will also be different. Micro planning is based on the concept that people should plan locally to obtain sustainable development. The micro planning model can be helpful to the teachers. They can identify the strengths and weaknesses, make plans accordingly to alter their teaching methods, and divert more efforts for teaching the slow learners.

For increasing the likeness for STEM among the parents, the micro planning can be done in three stages:

The first stage can analyze issues like the total number of students in the school and know the students with less attendance. Also, to know students' level of learning, subjects and teaching methods liked by the students, the problematic issues for the students to understand, the reasons for their disliking a topic, etc. Besides this, some parents may find it challenging to conduct STEM activities for their children at home.

The second stage will include finding out the reasons for the non-achievement of the students' learning goals. Though the reasons may be different, the parents' discussion can help identify various causes. These include teachers' unavailability if the teachers are using the newly developed teaching methods appropriately and poor curriculum design. Parents collectively can shed light on problems like the poor financial conditions of some students. They are unable to complete the STEM projects and fear among the kids for coming to school. Poor health of some students can also be a reason for their less involvement. Suppose the parents cannot conduct STEM activities assigned by the teachers. In that case, they can list the reasoning behind it, like language barriers, less education among parents, etc.

Parents know their children well, and therefore they can play a vital role in identifying the problems and similarly finding solutions. So, the third stage of micro planning will be identifying solutions for the issues listed out by them. Some of the answers can be improving children's health by arranging regular health checkups. They can also encourage child-centered teaching methods, group activities and make the school environment more attractive for children studying STEM subjects. It can also involve removing the language barriers for the parents to be comfortable with the STEM activities.

A committee of parents can be formed and they can monitor the improvements in the teaching learning process through regular monthly meetings. As the micro plan is prepared by the people, they will be more interested in knowing if their plans are working properly and automatically both the issues of parents involvement and difficulties faced by the students while studying STEM can be solved. (see Figure 8)

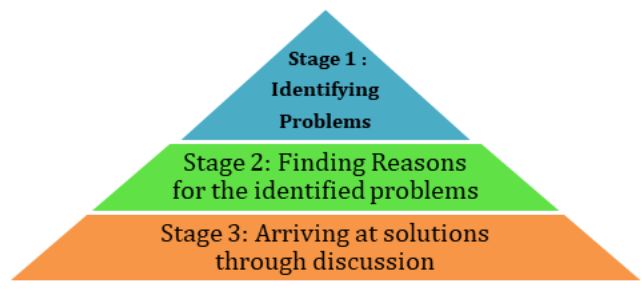

Figure 8 Stages of micro planning

\section{Encouraging students for STEM projects}

The early childhood classroom is a perfect place to provide a solid foundation of STEM to the kids. Exposure to STEM concepts during the early years can leave a long-term impact on the academic skills of curious young minds. It is therefore essential to boost the STEM skills of students with the help of singing, dancing, reading, and any other ways that would be interesting for the preschoolers. The learning and teaching methods, the techniques used for assessment, and the education curriculum followed by the educational institutions influence students' attitudes towards science. If these factors are not necessary, the students may lose interest in science and math and start considering these subjects as complex at an early age or during preschool days (The Institution of Engineering \& Technology, 2008). The laboratorybased methods for teaching science in schools should complement the out-of-school learning that would expose the students to the actual world. Science and Technology lessons can be made attractive to the students at an early age by using modern information technology tools and gadgets. Several activities can be taken for the preschoolers and the kids to develop a liking for the STEM subjects. Parents and teachers should realize that young minds love to explore and learn new things. The learning process can be made interesting by inculcating the STEM activities as a part of the daily routine. The kids should be involved in the activities that 
are a part of their day-to-day life, and at the same time, they learn the STEM concepts with their experiences. Besides this, there should be project competitions to use their novel ideas to develop innovative projects. The students should be provided lab facilities in school to perform experiments. At the same time, they should be provided with financial support to carry out their projects and given incentives in exams.

\subsection{STEM activities for preschoolers}

(1) A nature walk can be an exciting activity for preschoolers. During the walk, the student can take a bag to collect some exciting objects like flowers, leaves, stones, etc. This bag can be emptied at home. The objects can be classified according to color or shapes; they can also count the number of things of a specific type. This activity can help in improving science and math for young minds.

(2) Another activity can be allowing the kids into the kitchen and allowing them to help the elders in doing some cooking. The jars in the kitchen can be labeled so that they know the names of the food items present at home, and at the same time, they can learn different colors They can be engaged in cooking activities so that they learn about measuring and mixing. (see Figure 9)

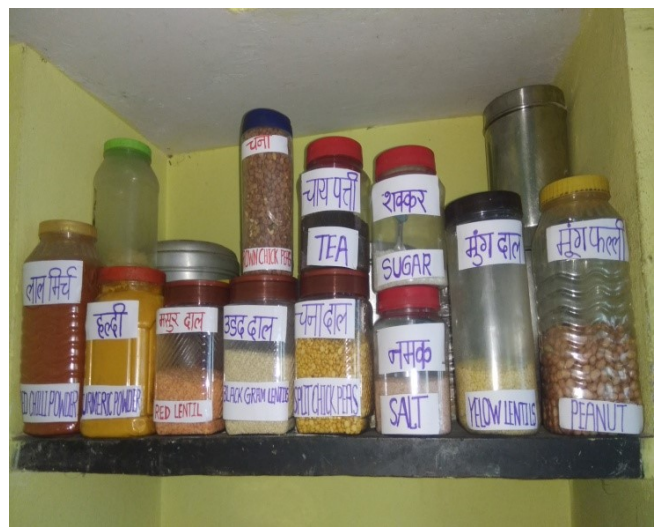

Figure 9 Containers with food items in kitchen labeled in English and local language

(3) To develop their engineering and mathematics skills, they can be assigned some challenges. These include building towers using paper cups, constructing geometric shapes using toothpicks, making three-dimensional structures, etc. They can also create different configurations, animals, fruits, flowers, animals using clay.

(4) Children love to visit grocery stores with their parents. This can be considered an activity in which the children will explore fruits and vegetables in the store, know their names and prices, and try to calculate the bills at the end of shopping. This would be again an activity to improve their skills for math and science through which they learn to identify the fruits and vegetables and remember calculations. Similarly, knowledge of animals and birds of various kinds can be encouraged through visits to zoos and wildlife sanctuaries.

(5) Kids love playing with water, and this attribute too can be used as an opportunity to engage them in STEM learning. They can be left to play with water and measuring cups, bottles, or jars of different capacities. They can learn to measure the liquids in liters, milliliters, etc.

\subsection{STEM activities for children at early school days}

Group activities rather than individual learning should be encouraged for the kids. They should be exposed to real-life learning resources rather than the formal school environment. The STEM activities can be enjoyable for the students if they are not bound to the class curriculum and complete their tasks. In addition to this, the STEM activities should be flexible. The students should be allowed to put their knowledge into it. Awareness for STEM can be generated by initiating activities related to daily life and will be helpful for the students and their family members (Wahyudi \& Padmi, 2019). The students should be given incentives in the form of extra marks for carrying out the STEM projects. They should receive appreciation for their work. Gratitude and acknowledgements will boost up the confidence of children and will improve their performance. This section will discuss the activities that will be useful for the students at the primary/elementary levels.

(1) Hand-wash stations should be installed in all the schools. Managing the hand wash stations can be a helpful STEM activity. There should be posters near the hand-wash stations to 
display the correct steps of hand-washing. Besides this, the maintenance of hand-wash stations can be assigned to a group of students. These students will keep the hand-wash stations clean. Their skills in science and technology can be enhanced by encouraging them to think of options to prevent the wastage of water. Wastage of water can be avoided by diverting the water from hand-wash stations towards the kitchen garden. The students can use a low-cost filter made from charcoal or sand that will be used to filter the water coming out of the hand-wash stations.

(2) They can be encouraged to do a small survey to study water usage and availability in their area. They can collect data on the number of taps and other water resources in the locality. Furthermore, try to know how many of them are in good condition, how many sides of the area are leaking, or how many are not used for household chores requiring water. When conducted under the guidance of teachers, such surveys can help improve their abilities in mathematical calculations. The students can collect data from their locality and then combine the data collected, which can help them compare water usage in different areas of the town/village. The students can use this data to know about the reasons for existing water scarcity in their villages So, they learn comparison techniques, arithmetic calculations, and the importance of water in their life.

(3) Another exciting activity for the students can be taking care of the vermicompost plant in the school. The students can be encouraged to bring the kitchen waste for the vermicompost. This activity will develop their science skills to know about the diverse types of garbage generated in a house. They will learn closely about decomposition and will learn to use vermicompost as a tool for waste management.

(4) All the plants in the school garden should be labeled. The students should be allowed to water the plants under the guidance of teachers. By this activity, the students will learn the names of plants, know about the importance of water in plants' growth, and understand the concept of photosynthesis.

(5) The students can learn the germination process by placing some seeds in a jar. Then by monitoring the process every day, noticing the seed's changes, and learning how a seed is converted into a plant.

(6) The students can be encouraged to make rain gauges at home. The homemade rain gauge can be made with the help of a cylindrical transparent bottle with a funnel at its opening, which will have measurement levels marked on it. The rain gauge can be kept at an even surface, preferably on the roofs or high places, to record the rainfall without disturbances. Areas with more trees should be avoided. The rain gauge can help collect rainfall data in a village weekly, monthly, and annually. These rain gauges will be an essential tool to develop the science and math ability of kids and, at the same time, will help their families to plan their agricultural activities and plan for the conservation of water.

(7) The games period can be a source of improving the STEM skills. Some of the STEM concepts that can be explained through games are:

a. The theory of gravitation can be explained by telling them how the ball comes back to the earth when it is thrown in the air.

b. Games like hockey, football, baseball, and hockey can introduce the concepts of speed, distance, time, force, and momentum. For example, while playing football, the time required by the ball to reach the goal will depend on the pressure exerted by the player for kicking the ball. Furthermore, it depends on the ball's speed and the distance between the ball and the goal Newton's laws of motion are essential for launching rockets and are equally crucial for games like football and baseball.

\section{Addressing gender gap in STEM education}

The STEM fields that offer the highest-paid jobs like engineering and computer science are male-dominated. The gender gap in the STEM field is widened by the gender stereotypes in which the parents and teachers underestimate the abilities of girls to study math and science. These stereotypes are one of the reasons the girls have less interest in STEM subjects, and they do not continue with this field for long. As few women choose STEM careers, few role models are available to the girls to inspire them. Due to these factors, most girls leave STEM education early and continue their education in other fields. In addition to this, several girls drop their education after a few years of early education. Therefore, very few women succeed in choosing STEM as their career option. This issue can be solved by improving girls' beliefs at an early age during the school days. They should be more confident of their abilities to make good decisions about their future and not step out or change their choices for STEM education under societal pressure.

An effective education curriculum ensures equal motivation and a cheerful outlook about 
STEM subjects for both boys and girls (Savinskaya, 2017). Equal opportunities for education and career are vital factors to ensure sustainable development for a nation. According to Pew research center, STEM jobs earn two-thirds more than those in other fields. For a gender reduction gap and to improve women's economic security, girls must be encouraged to continue with STEM education for higher levels of education.

\subsection{Challenges of female education}

However, girls have to face several challenges to continue with their education as they grow up. There is a need to enhance awareness among the parents and community, especially in the rural areas, to encourage the girls to continue their education and decrease the number of girl dropouts. To address the gender gap in the STEM field, the causes of girl dropouts are essential to be identified. Though the Governments have taken several initiatives to encourage girls for science and technical education, the retention of girls in the STEM field remains a challenge. The traditional beliefs, stereotypes, societal pressure, and some unnoticed factors that compel the girls to discontinue their education should be figured out for reducing the gender gap in STEM.

The rural areas have schools with primary education. To continue with education after the elementary level, they must travel to nearby places. It generates insecurity among the parents and the money required for travel, which exerts a financial burden for the weaker economic sections. The institutions providing technical education are confined to cities. The establishment of higher education or technical institutes near the villages can be helpful for the girls who are unable to travel long distances. Disseminating awareness among the parents regarding the benefits of STEM education for girls is extensively required to concentrate more on their daughters' education rather than being under societal pressure or thinking about the education expenses as a financial burden.

An issue that remains unaddressed most of the time is the school's lack of proper sanitation facilities. Many studies have revealed the lack of toilets in school as one of the reasons for more girl dropouts after elementary education. These problems can be addressed by developing infrastructure and additional financial support to encourage the girls to continue their education. Early marriages or child marriage is a custom prevalent in the rural areas that stop the girls from continuing their education. Few social taboos persist in some communities that have increased the challenges of implementing activities that would help retain girls in school. One of such social taboos is that some parents hesitate to send girls to co-ed schools. They do not like the presence of male teachers in school, especially while studying topics related to sexual or menstrual health. So again, there is a need to increase the number of female teachers to teach science. Some other beliefs that keep girls away from school are that girls are made for doing household work. If the girls are educated, they will leave their homes for jobs without fulfilling family responsibilities. So, some parents prefer to discontinue their daughters' education and teach them to do most household work. In the rural areas, the elders go out for work, and then the girls are left at home to take care of their siblings and complete the chores, due to which they do not attend the classes regularly. Therefore, due to the social taboos, the girls are unable to get a proper atmosphere to learn.

\subsection{Importance of STEM learning for girls}

Technological advancements and innovations have increased the standard of living, and everything is available at our fingertips. This development cannot be long lasting if half of the workforce, i.e., the females of the world, are excluded. The number of girls in STEM is gradually increasing, but the number of boys is also growing simultaneously. The gender gap may have reduced in the last decade, but still, the gap formed for so many years is difficult to erase. The technological advancements are due to the research going on in the field of STEM. Still, to live in a world of more innovations and inventions, the capabilities of the women task force cannot be neglected. This section will discuss some of the reasons identified in a recent report by UNICEF for encouraging girls to STEM (United Nations Children Fund, 2020). Learning of STEM is not limited to only advanced applications, gadgets, or inventions. It is a medium to develop critical thinking and critical thinking skills. The science subjects impart knowledge about nutrition and health issues. In developing countries, a large population residing in the villages or hamlets is unaware of basic sanitation and menstrual hygiene. They are living with stereotypes and not ready to change their beliefs for improving their health. Malnourishment, infant mortality, prenatal and postnatal deaths are still significant issues in some parts. If the girls are educated, they will gain knowledge about nutrition, sanitation, and hygiene. They can 
take care of themselves as well as their families. Learning science by girls can therefore be considered as a key to good health.

Education is not just about learning to read and write. It provides an ability to judge things and transform the acquired knowledge for the benefit of humankind. Numerical skills are a part of STEM education. When the girls learn numerical skills, they can use them to monitor their health, like studying their menstrual patterns and keeping track of the weight chart of babies. These numerical skills will also help make financial decisions for families about planning for monthly expenses and savings. Besides the chores of day-to-day life, numerical skills play a significant role in coding and robotics. The girls can try to develop new models for solving the problems of the real world. Thus, STEM allows girls to become knowledgeable citizens and build their decisive and leadership qualities.

When we live in a world surrounded by gadgets, STEM education is an opportunity of obtaining and using digital literacy in day-to-day life. The internet is an excellent platform for searching and learning new concepts. If the girls acquire technical knowledge, they can easily use modern gadgets, surf the internet to understand, and interact online with others, remaining safe and healthy. Access to technology can transform girls' thinking. They can emerge as change makers to give a new dimension to society's social, cultural, political, and economic environment. The step to the empowerment of girls begins at an early age. We live in a society where the toys and colors are distinguished by gender, like pink and dolls for girls or cars for boys. The time has come to get out of this gender-specific role and encourage girls to play with puzzles and Lego blocks to develop their creativity from childhood days.

\subsection{Role of teachers}

Teachers can play a vital role in promoting gender equality and ensure equal participation of students irrespective of their gender during class activities. A study conducted by the Institute of Education Sciences (Halpem et al., 2007). has discussed the role of teachers as given below:

(1) Girls lose confidence in STEM subjects due to the difficult conditions they face to continue their education. Teachers can improve the confidence of girls by making them aware that their academic abilities are not limited. The teachers should help the girls realize that gender roles prescribed by society cannot alter their academic skills and talents.

(2) Another step that the teacher can take to improve students' performance is to provide them with feedback. Positive feedback can motivate the girls as they will be content to learn that their performance is equal or better than their male counterparts.

(3) Girls have grown up with the belief that STEM careers are made for men. The teachers can erase this belief from the young brains by exposing them to role models who have achieved heights by choosing STEM. An interaction session with these role models and helping them to read biographies of successful women in science and engineering fields can encourage the girls to get rid of the stereotypes.

(4) With each workout, teachers can choose the activities wisely to improve their interest in science, math, and engineering subjects. The exercises should be selected according to the girl's interests not to lose interest in these subjects. These activities should fuel up the curiosity levels of the girls for STEM subjects. The teachers can identify the girls exhibiting more interest in STEM and formulate strategies to make all the resources available to improve their interest level. At the same time, the girls can be made aware of careers and higher education opportunities available in this field.

(5)The spatial skills go through a significant expansion phase during early childhood, i.e., from zero to eight years. The interventions done at an early age are more effective than the ones arriving late in life. Teachers can encourage girls in early school days for spatial skills training to improve their performance in science and mathematics.

\section{Conclusion}

Education is called to qualify students for the knowledge that will enable them to proceed from the simple consumption and use of technological products to their critical analysis, even giving technological solutions (Dorouka et al., 2021). Introducing the kids to STEM education in the early years of life is a step towards developing their problem-solving and critical thinking skills. It is better to start STEM learning at a young age as the children can learn quickly in the initial five years. STEM can be made interesting by teaching it through games, activities, and play. Implementing innovative teaching methods for STEM is challenging in rural areas due to a lack of awareness and a shortage of funds. These problems can be solved by disseminating awareness among the masses regarding the benefits of STEM in strengthening the economic 
status of home and country. At the same time, it is essential to encourage the students for real-life projects through which they would learn science and math concepts through real-life experiences. Equal participation of girls in the STEM learning process and reducing the gender gap in the STEM field are essential for sustainable development. The girls should be encouraged to learn STEM subjects from childhood and continue with it for the rest of their lives to choose it as a career option in the future.

Despite rapid advancements, education maintains an outdated system in the current technological, economic, and social conditions. However, an international effort is to reform curricula encouraging innovative teaching models in primary education that promote STEM education and computational thinking as a problem-solving method (Papadakis \& Kalogiannakis, 2019). Students need skills (often referred to as 21st-century skills) to help them cope with modern society's demands. Robotics enhances critical thinking, computational thinking, problem-solving, algorithmic thinking, making decisions, creativity, and collaboration. Educational robotics provides opportunities by integrating many subjects besides science, technology, engineering, and mathematics, such as art, dance, music, and more, and therefore its integration into formal learning is reasonable (Papadakis et al., 2021).

\section{Acknowledgements}

The authors would like to acknowledge the Gram Panchayat (Elected Village Body) of Pellora Village in Chandrapur Distrct of Maharashtra, India for their support in completing this chapter.

\section{Conflict of Interest}

The authors declare that there is no conflict of interest.

\section{References}

Ampartzaki, M., Kalogiannakis, M., \& Papadakis, S. (2021). Deepening Our Knowledge about Sustainability Education in the Early Years: Lessons from a Water Project. Education Sciences, 11(6), 251. https://doi.org/10.3390/educsci11060251

Bubikova-Moan, J., Næss Hjetland, H., \& Wollscheid, S. (2019). ECE Teachers' views on play-based learning: a systematic review. European Early Childhood Education Research Journal, 27(6), 776-800. https://doi.org/10.1080/1350293X.2019.1678717

Chatzopoulos, A., Kalogiannakis, M., Papadakis, S., Papoutsidakis, M., Elza, D., \& Psycharis, S. (2021) DuBot: An Open-Source, Low-Cost Robot for STEM and Educational Robotics. In Handbook of Research on Using Educational Robotics to Facilitate Student Learning (pp. 441-465). IGI Global. https://doi.org/10.4018/978-1-7998-6717-3.ch018

Dorouka, P., Papadakis, S., \& Kalogiannakis, M. (2021). Nanotechnology and mobile learning: perspectives and opportunities in young children's education. International Journal of Technology Enhanced Learning, 13(3), 237-252. https://doi.org/10.1504/IJTEL.2021.115975

Douma, K. B., \& Adler, K. (2020). Leading Change: Microplanning to Customize Student Learning. New Jersey English Journal, 9(1), 5.

Ejiwale, J. A. (2013). Barriers to successful implementation of STEM education. Journal of Education and Learning, 7(2), 63-74. https://doi.org/10.11591/edulearn.v7i2.220

Halpern, D., Aronson, J., Reimer, N., Simpkins, S., Star, J., \& Wentzel, K. (2007). Encouraging Girls in Math and Science (NCER 2007-2003). Washington, DC: National Center for Education Research, Institute of Education Sciences, US Department of Education. http://nces.ed.gov

Harris Interactive. (2016). STEM perceptions: Student \& parent study: Parents and students weigh in on how to inspire the next generation of doctors, scientists, software developers, and engineers.

Harris, R. S., \& Hodges, C. B. (2018). STEM Education in Rural Schools: Implications of Untapped Potential. National Youth-At-Risk Journal, 3(1), 3-12. https://doi.org/10.20429/nyarj.2018.030102

Lego Foundation. (2017). What we Mean by Learning Through Play, Version 1.2.

McClure, E. R., Guernsey, L., Clements, D. H., Bales, S. N., Nichols, J., Kendall-Taylor, N., \& Levine, M. H. (2017). STEM starts early: Grounding science, technology, engineering, and math education in early childhood. New York: The Joan Ganz Cooney Center at Sesame Workshop.

Padmi, M. R. S., \& Salmah, M. U. STEM Village: Promoting and Spreading Awareness about STEM to Families and the Society. Reform and Development in Teacher Education for the Digital Society. 
Papadakis, S. (2020). Evaluating a Teaching Intervention for Teaching STEM and Programming Concepts Through the Creation of a Weather-Forecast App for Smart Mobile Devices. In Handbook of Research on Tools for Teaching Computational Thinking in P-12 Education (pp. 31-53). IGI Global. https://doi.org/10.4018/978-1-7998-4576-8.ch002

Papadakis, S. (2021). Advances in Mobile Learning Educational Research (AMLER): Mobile learning as an educational reform. Advances in Mobile Learning Educational Research, 1(1), 1-4. https://doi.org/10.25082/AMLER.2021.01.001

Papadakis, S., \& Kalogiannakis, M. (2017). Evaluation of Greek android mobile applications for preschoolers. Preschool and Primary Education, 5(2), 65-100. https://doi.org/10.12681/ppej.11208

Papadakis, S., \& Kalogiannakis, M. (2019). Evaluating the effectiveness of a game-based learning approach in modifying students' behavioural outcomes and competence, in an introductory programming course. A case study in Greece. International Journal of Teaching and Case Studies, 10(3), 235-250. https://doi.org/10.1504/IJTCS.2019.102760

Papadakis, S., \& Kalogiannakis, M. (2020). Exploring Preservice Teachers' Attitudes About the Usage of Educational Robotics in Preschool Education. In the Handbook of Research on Tools for Teaching Computational Thinking in P-12 Education (pp. 339-355). IGI Global. https://doi.org/10.4018/978-1-7998-4576-8.ch013

Papadakis, S., \& Kalogiannakis, M. (2020). Learning computational thinking development in young children with Bee-Bot educational robotics. In Handbook of research on tools for teaching computational thinking in P-12 education (pp. 289-309). IGI Global. https://doi.org/10.4018/978-1-7998-4576-8.ch011

Papadakis, S., \& Kalogiannakis, M. (Eds.). (2019). Mobile learning applications in early childhood education. IGI Global. https://doi.org/10.4018/978-1-7998-1486-3

Papadakis, S., Kalogiannakis, M., \& Zaranis, N. (2021). Teaching mathematics with mobile devices and the Realistic Mathematical Education (RME) approach in kindergarten. Advances in Mobile Learning Educational Research, 1(1), 5-18. https://doi.org/10.25082/AMLER.2021.01.002

Papadakis, S., Vaiopoulou, J., Sifaki, E., Stamovlasis, D., \& Kalogiannakis, M. (2021). Attitudes towards the Use of Educational Robotics: Exploring Pre-Service and In-Service Early Childhood Teacher Profiles. Education Sciences, 11(5), 204. https://doi.org/10.3390/educsci11050204

Papadakis, S., Vaiopoulou, J., Sifaki, E., Stamovlasis, D., Kalogiannakis, M., \& Vassilakis, K. (2021). Factors That Hinder in-Service Teachers from Incorporating Educational Robotics into Their Daily or Future Teaching Practice. In CSEDU (2) (pp. 55-63). https://doi.org/10.5220/0010413900550063

Poultsakis, S., Papadakis, S., Kalogiannakis, M., \& Psycharis, S. (2021). The management of Digital Learning Objects of Natural Sciences and Digital Experiment Simulation Tools by teachers. Advances in Mobile Learning Educational Research, 1(2), 58-71. https://doi.org/10.25082/AMLER.2021.02.002

Pyle, A., Poliszczuk, D., \& Danniels, E. (2018). The challenges of promoting literacy integration within a play-based learning kindergarten program: Teacher perspectives and implementation. Journal of research in childhood education, 32(2), 219-233. https://doi.org/10.1080/02568543.2017.1416006

Savinskaya, O. B. (2017). Gender equality in preschool STEM programs as a factor determining Russia's successful technological development. Russian Education \& Society, 59(3-4), 206-216. https://doi.org/10.1080/10609393.2017.1399758

Susilo, H., \& Sudrajat, A. K. (2020, June). STEM Learning and its Barrier in Schools: The Case of Biology Teachers in Malang City. In Journal of Physics: Conference Series (Vol. 1563, No. 1, p. 012042). IOP Publishing. https://doi.org/10.1088/1742-6596/1563/1/012042

Tay, J., Salazar, A., \& Lee, H. (2018). Parental perceptions of STEM enrichment for young children. Journal for the Education of the Gifted, 41(1), 5-23. https://doi.org/10.1177/0162353217745159

Teaching Tolerance Project. (1997). Starting Small: Teaching tolerance in preschool and the early grades. Alabama: Southern Poverty Law Center.

The Educational Value of Alumni for Public High Schools. (2019). UC San Diego's Center for Research in Educational Equity, Assessment and Teaching Excellence (CREATE).

The Institution of Engineering \& Technology. (2008). Studying STEM: What are the Barriers. https://mei.org.uk/files/pdf/Studying_Stem.pdf

The Lego Foundation in Support of UNICEF. (2018). Learning Through Play, Strengthening Learning Through Early Play in Early Childhood Education Programs.

Torres-Crespo, M. N., Kraatz, E., \& Pallansch, L. (2014). From Fearing STEM to Playing with It: The Natural Integration of STEM into the Preschool Classroom. SRATE Journal, 23(2), 8-16.

Tzagkaraki, E., Papadakis, S., \& Kalogiannakis, M. (2021). Exploring the Use of Educational Robotics in primary school and its possible place in the curricula. In Educational Robotics International Conference (pp. 216-229). Springer, Cham.

https://doi.org/10.1007/978-3-030-77022-8_19

UNICEF. (2020). Towards an equal future: Reimagining girls' education through STEM. New York. 
United Way Mumbai and CSR Box. (2018). Perspectives on Better Education through CSR, in India, Assessment of needs \& opportunities for investment in education. Retrieved from https://www.unitedwaymumbai.org/downloads/Perspectives

US Department of Education in Collaboration with American Institutes for Research. (2015). STEM 2026: A Vision for Innovation in STEM Education.

Vaiopoulou, J., Papadakis, S., Sifaki, E., Stamovlasis, D., \& Kalogiannakis, M. (2021). Parents’ Perceptions of Educational Apps Use for Kindergarten Children: Development and Validation of a New Instrument (PEAU-p) and Exploration of Parents' Profiles. Behavioral Sciences, 11(6), 82. https://doi.org/10.3390/bs11060082

Van Voorhis, F. L., Maier, M. F., Epstein, J. L., \& Lloyd, C. M. (2013). The impact of family involvement on the education of children ages 3 to 8 : A focus on literacy and math achievement outcomes and social-emotional skills. MDRC.

Vidakis, N., Barianos, A. K., Trampas, A. M., Papadakis, S., Kalogiannakis, M., \& Vassilakis, K. (2019). in-Game Raw Data Collection and Visualization in the Context of the "ThimelEdu" Educational Game. In the International Conference on Computer Supported Education (pp. 629-646). Springer, Cham.

https://doi.org/10.1007/978-3-030-58459-7_30 